Fifth International Conference on Sustainable Construction Materials and Technologies. http://www.claisse.info/Proceedings.htm

\title{
THE EFFECTS OF FORMWORK TYPES AND CURING PERIOD ON THE CONCRETE SURFACE QUALITY
}

\author{
Akari Shibuya $^{1 *}$, Shinya Kitagawa ${ }^{2}$ and Takeshi Iyoda ${ }^{3}$ \\ 13-7-5, Toyosu, Koto-ku, Tokyo 135-8548, Japan, \\ ah15047@shibaura-it.ac.jp, Shibaura Institute of Technology. \\ 2 4-12-19, Nihonbashi-Honcho, chuo-ku, Tokyo, Japan, \\ s.kitagawa@satokogyo.co.jp, Sato Kogyo Co., Ltd., \\ ${ }^{3}$ 3-7-5, Toyosu, Koto-ku, Tokyo 135-8548, Japan, \\ iyoda@shibaura-it.ac.jp, Shibaura Institute of Technology.
}

\begin{abstract}
Quality of the surface concrete layer is important to keep durability of concrete structure. The beauty of concrete surface is also important. However, there are many cases that some initial defects occur. The past research has reported that using formworks coated by water repellent preparation and lengthening compaction time by vibration are able to reduce surface bubbles. In this research, we changed formwork types and curing periods. We considered what is affecting between surface bubbles and denseness of surface layer. As a result, surface bubble ratio depends on different formwork types, but the denseness of concrete didn't affect by types of formworks. On the other hand, quality of surface concrete strongly depended on curing periods. We measured elastic wave velocity by the ultrasonic speed measurement tool for estimating denseness of concrete. There was a good relationship between elastic wave velocity and air permeability and water permeability on surface concrete layer.
\end{abstract}

Keywords: the quality of the surface layer of concrete, surface bubbles, formworks, elastic wave velocity 


\section{INTRODUCTION}

In the concrete structure, the quality of the surface layer of concrete is regarded as important. Surface layer quality refers to mass transfer resistance, strength characteristics, chemical properties and aesthetic appearance in concrete structures. In recent years, even civil engineering structures have been designed with consideration of landscapes, not only structural functions but also good appearance are required. Among them, the beauty of concrete is important for concrete structures. There are surface bubbles as those that affect aesthetics. Also, mass transfer resistance is considered to affect the durability of concrete structures, and it is thought that compactness is related. Previous studies have reported that surface bubbles can be reduced by using a mold coated with a water repellent material or lengthening compaction time with a vibrator. Furthermore, it is known that setting the curing period improves the compactness of the surface layer of concrete. However, it is not clear what is affecting the aesthetic appearance and the compactness of the surface layer of concrete. In this research, we changed formwork types to change the aesthetic appearance and curing periods. We consider whether aesthetic appearance and the compactness of the surface layer of concrete depend on, and we classify the results into influence of formwork types and influence of curing periods.

\section{MATERIALS AND SPECIMENS CONDITION}

The specified mix proportion is indicated in the Table 1. The blast-furnace slag cement is replaced $42.5 \%$ of ground granulated blast furnace slag (GGBFS) for this research. The water cement ratio was set high to appear impact of curing. We used five types of formwork in Table 2, and it is represented by abbreviated name. The specimen size is two kinds, $225 * 225 * 55(\mathrm{~mm})$ for freeze-thaw testing and $300 * 300 * 150(\mathrm{~mm})$ for other tests. This concrete is casted 2 layer, and the compaction is for 15 seconds by the vibrator. The demolding time is 18 hours and 2days. The former is the fastest time when tunnels is constructed. After demolding, the specimens are cured for 3 or 7 days by plastic wrap to change surface layer. These conditions indicated in the Fig.1.

Table 1. Mix Proportion

\begin{tabular}{|l|c|l|}
\hline Water/Cement $(\%)$ & $\begin{array}{c}\text { Sand } / \\
\text { Total }\end{array}$ & Quantity per unit volume of concrete $\left(\mathrm{kg} / \mathrm{m}^{3}\right)$ \\
\hline
\end{tabular}




\begin{tabular}{|c|c|l|c|c|c|c|}
\hline & aggregate(\%) & & & & \multicolumn{2}{|c|}{ Water } \\
\cline { 5 - 7 } & & Water & & & & \\
\hline 60 & 48 & 170 & 60 & 48 & 170 & 60 \\
\hline
\end{tabular}
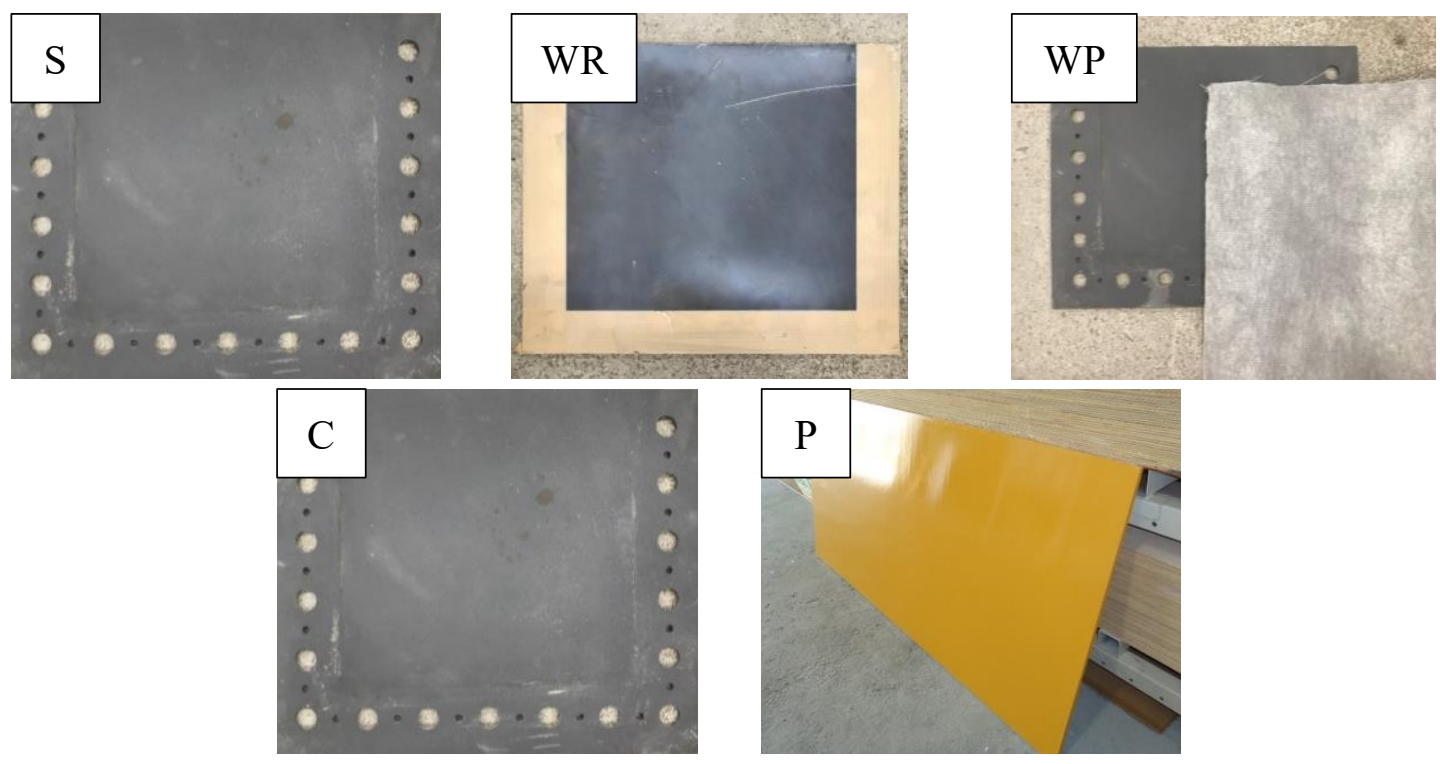

Figure 1. Pictures of each formworks

Table 2. Formwork Types

\begin{tabular}{|c|c|c|c|c|}
\hline Formwork type & Abbreviation & Material & Details & $\begin{array}{c}\text { Release agent } \\
\text { application }\end{array}$ \\
\hline Steel & $\mathrm{S}$ & \multirow{4}{*}{$\begin{array}{l}\text { solid } \\
\text { steel } \\
\text { plate }\end{array}$} & - & $\checkmark$ \\
\hline Water Repellent & WR & & water repellent & $x$ \\
\hline Water Permeable & WP & & permeable sheet & $x$ \\
\hline Ceramic & $\mathrm{C}$ & & ceramic coating & $\checkmark$ \\
\hline Plywood & $\mathrm{P}$ & plywood & - & $x$ \\
\hline
\end{tabular}




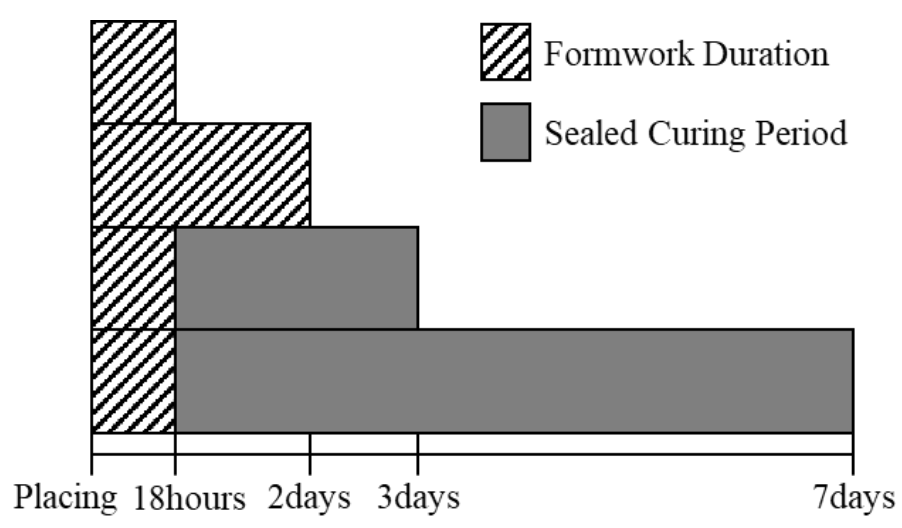

Fig.2 Demolding times and curing period

\section{OUTLINE of EXPERIMENT}

3.1 Surface Bubble Ratio. We calculate surface bubble ratio by binarization of the surface images. Binarization is the process of converting the image to black and white. However, the mesh pattern is reflected on the specimen of permeable formwork, and it is not possible to digitize correctly. Therefore, the surface bubble ratio is expressed by the threshold processed at a brightness of $40 \%$.

3.2 Freeze-thaw Testing. The freeze-thaw testing compliant with ASTM C672. We make a bank with sealing material 28 days after casting, and we put water up to $6 \mathrm{~mm}$ in height. It is frozen in the freezer for 17 hours, and it is thawed in the constant temperature of $20^{\circ} \mathrm{C}$ and humidity of $60 \%$ chamber for 7 hours. Therefore, 1 cycle is 24 hours, and we test 30 cycles. We collect scaling strips peeled from the test surface, and compare strips weight of material per unit area.

3.3 Measuring of Surface Moisture Content. The moisture content of the concrete surface was measured by measuring equipment. The measurement result is calculated as a percentage, and the larger the value, the more water is contained. We measure 3 places, upper, middle and lower with the casting side up, and take the average of 3 times at each place. In this research, values of middle place are indicated.

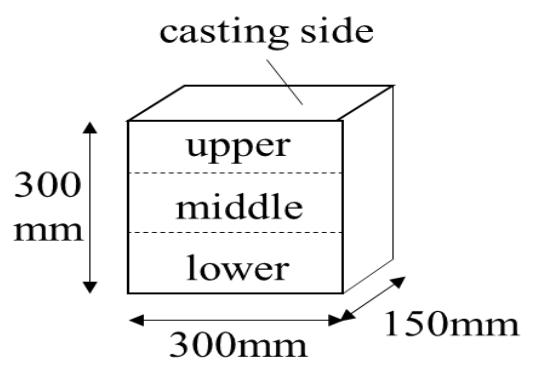

Figure 3. Measuring place of surface moisture content 
3.4 Surface Strength Test. The surface strength was measured by using Schmidt hammer. It is possible to measure repellency. The places of measuring and using values are same as surface moisture content test. The estimated strength formula is indicated below.

$$
\mathrm{F}\left(\mathrm{N} / \mathrm{mm}^{2}\right)=-18.0+1.27 \times(\text { Repellency })
$$

3.5 Air Permeability Test. Air permeability is tested with the Torrent method. We test it after checking $5 \%$ of surface moisture content on 28 days after casting. The evaluation standard is indicated in Table 3. Incidentally, the general lamination concrete is "bad".

Table 3. The Evaluation Standard

\begin{tabular}{|c|c|c|c|c|c|}
\hline $\begin{array}{c}\text { Surface air permeability } \\
\text { coefficient }\end{array}$ & Excellent & Good & General & Bad & Extreme \\
\hline $\mathrm{KT}\left(* 10^{\wedge}(-16) \mathrm{m}^{2}\right)$ & $0.001 \sim 0.01$ & $0.01 \sim 0.1$ & $0.1 \sim 1$ & $1 \sim 10$ & $10 \sim 100$ \\
\hline
\end{tabular}

\subsection{Simple Water Absorption Test}

This test compliant with JSCE-K 571 2013. The test instruments are fixed in the center of each specimen with sealing materials. They are put in water and we measure the amount of reduced water (water permeability) every hour. After measuring, we put water in instruments again not to change the permeation pressure due to position head. The measurements are made up to 12 hours.

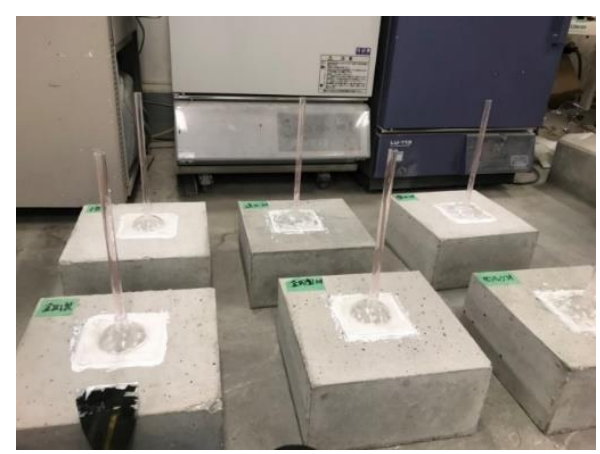

Fig.4 The instruments of this test 


\subsection{Elastic Wave Velocity}

The instrument of measuring ultrasonic sound speed is used. The places of measuring and using values are same as surface moisture content test.

\section{RESULTS AND DISCUSSIONS}

\subsection{Influence of Formwork Types}

(1) Surface bubble ratio. Table 4 indicates surface bubble ratio on target side by binarization. Water repellent formwork and water permeable are difficult to make surface bubbles. Others are similar larger values.

Table 4. Surface Bubble Ratio

\begin{tabular}{|c|c|c|c|c|c|}
\hline $\begin{array}{c}\text { Formwork } \\
\text { type }\end{array}$ & $\mathrm{S}$ & WR & WP & C & P \\
\hline $\begin{array}{c}\text { Surface } \\
\text { bubble } \\
\text { ratio(\%) }\end{array}$ & 3.1 & 0 & 0.3 & 2.4 & 2.1 \\
\hline $\begin{array}{c}\text { Binarized } \\
\text { image }\end{array}$ & $\cdots$ & & & & \\
\hline
\end{tabular}

(2) Freeze-thaw testing. Without water permeable formwork, the more cycles, the

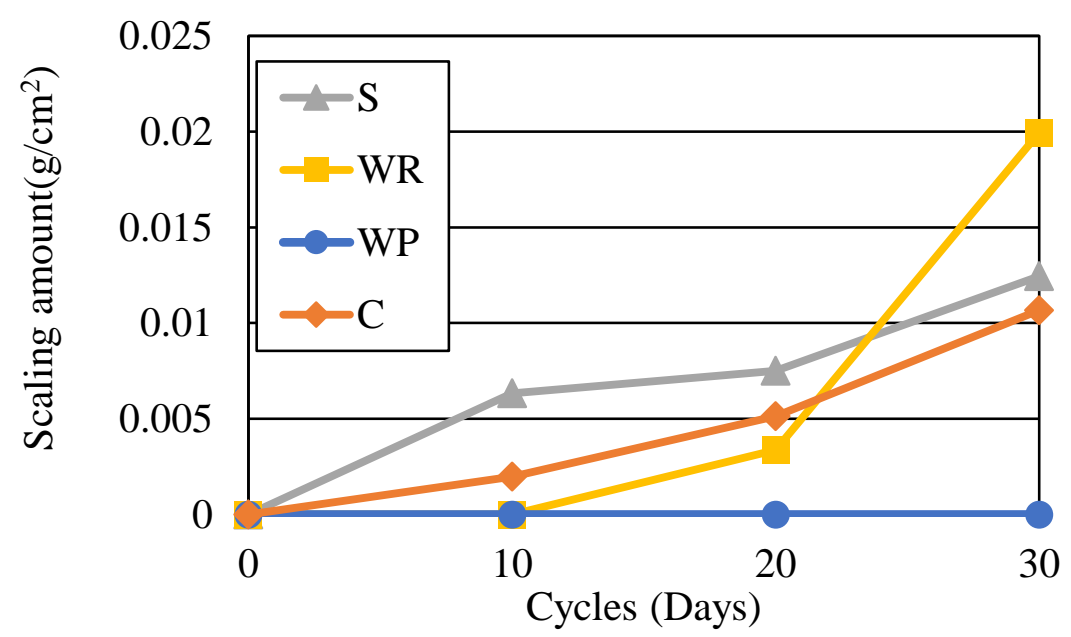

Fig.5 Scaling amount for each formworks 
more scaling amount. The formwork types caused differences in Scaling amount and cycles scaling occurred. In the case of water repellent formwork, scaling occurs later than others. However, it is known that once scaling occurs, surface deterioration speed is faster than others. The reason is that the surface water is pushed and returned by water repellent, and the film of cement paste is generated on the surface because aggregates go down. The cement paste is easy to expand and crack.

(3) Surface bubble ratio and scaling. Fig.6 indicates the relationship between surface bubble ratio and cycles scaling occurred. The higher the surface bubble ratio, the faster the scaling occurs. In this results, the case of water permeable formwork also does not apply. Furthermore, surface bubble ratio and cycles scaling occurred have a relationship.

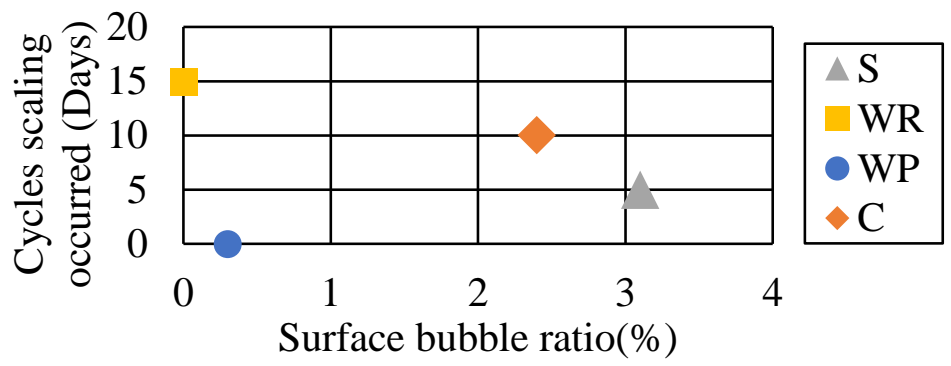

Fig.6 Relationship between surface bubble ratio and cycles scaling occurred

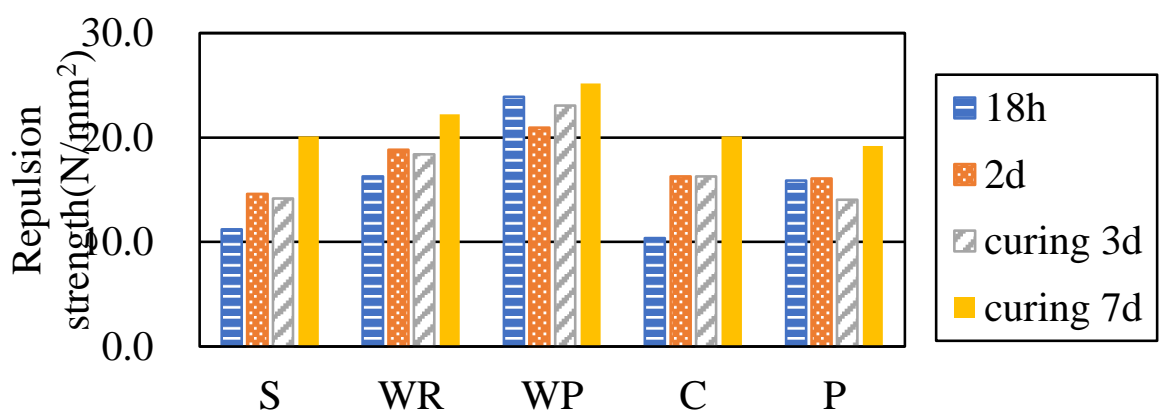

Fig.7 Repulsion strength

\subsection{Influence of Keeping Period of Concrete in the Formwork and Curing Period}

(1) Repulsion strength. Fig.7 indicates repulsion strength of concrete surface. The specimen using water permeability formwork is strongest surface in the all formwork types. In all cases, curing for 7 days is highest value, and there is a similar tendency. However, specimen using water permeability formwork and demolding 18 hours later from placing indicates high value. In the reason, the water of surface is sucked by 
permeability sheet, and W/C of surface drops.

(2) Air Permeability Test. The result of air permeability is indicated in Fig.8. All types of formwork are similar trend. Regardless of the type of formwork, it is more precise to lengthen curing. Also, all cases of demolding 18 hours later from placing are “extreme". (Table.3.) Additionally, keeping specimens without demolding for 2days and curing for 3 days are almost the same.

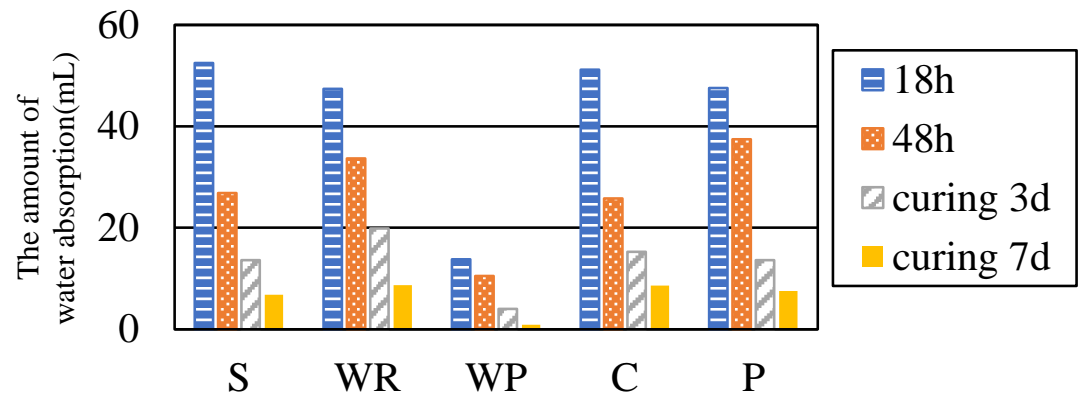

Fig. 8 The result of air permeability test

(3) Simple water absorption test. Fig.9 indicates the amount of water absorption for 12 hours. The case of water permeable formwork is different from the others. However, the others are similar amount. Furthermore, formwork types do not affect the compactness of the surface layer of concrete. Also, when Fig. 8 and Fig.9 are compared, the effect on curing is higher in the amount of water absorption.

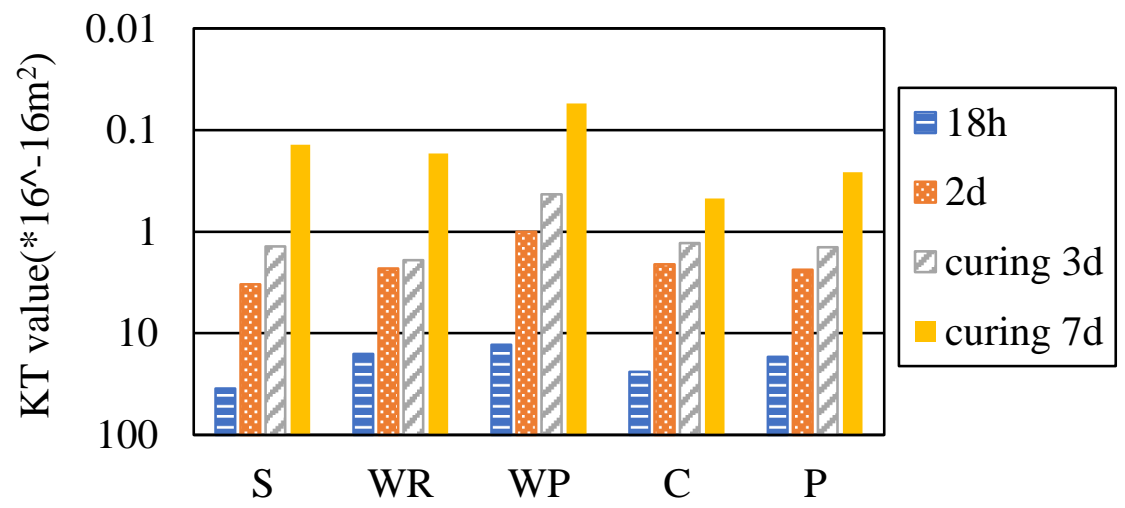

Fig.9 The result of simple water absorption test

(4) Elastic wave velocity and surface compactness. In indicated by Fig.10 and Fig.11, the ultrasonic speed correlates with air permeability and water absorption. There is no difference depending on the types of formworks without formwork of water permeability. Also, The longer curing period, the more compactly and larger value of ultrasonic speed. Furthermore, we are able to evaluate the compactness of concrete 
surface layer by using the instrument of measuring ultrasonic sound speed.

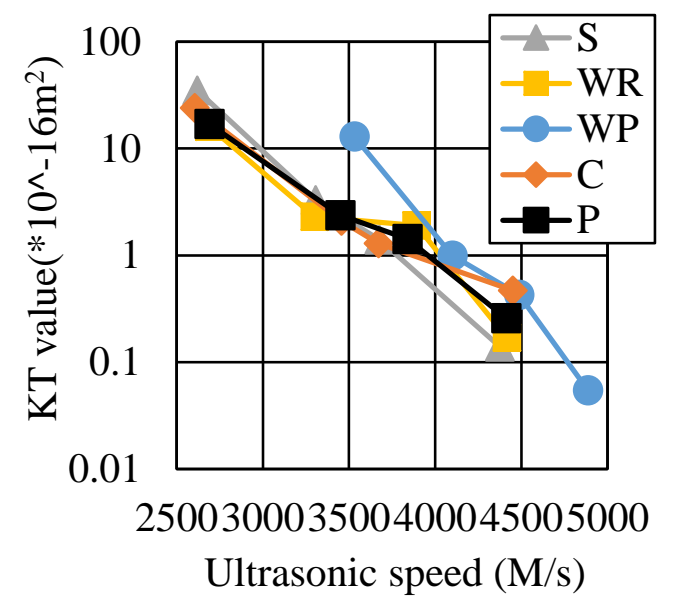

Fig. $10 \mathrm{KT}$ value and ultrasonic speed

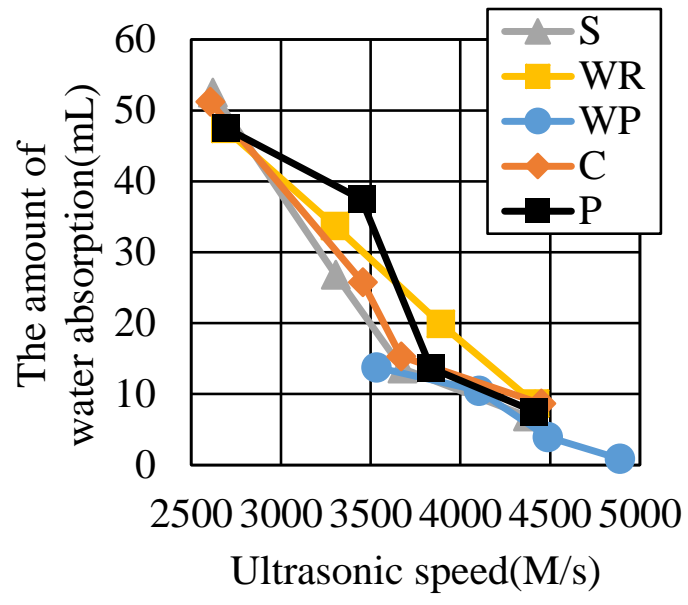

Fig.11 Water absorption and ultrasonic speed

\section{CONCLUSION}

(1) The types of formwork affect surface bubbles of concrete. However, it does not affect compactness.

(2) The lower the surface bubble ratio, the later the scaling begins to occur. The amount of scaling does not depend on the surface bubbles.

(3) The surface bubble radio does not affect air permeability and water absorption. Therefore, substance permeability of concrete does not depend on surface bubbles, and curing affects.

(4) The ultrasonic speed of specimen using the formworks except the water permeable formwork are almost no difference. Therefore, the compactness of the surface layer of concrete do not depend on the types of formwork, and the curing period is important to compact the surface layer.

(5) As indicated above, the case of water permeability formwork indicates different trends. Specifically, it is different for all tests except the air permeability test. The water condition of surface is important.

(6) Concrete using water permeable formwork shows features different from those of other forms.

\section{ACKNOWLEDGMENTS}

We would like to thank Mr. Takumi Kakinuma, Shibaura Institute of Technology 
graduates, for this research.

\section{REFERENCES}

Maho O., Takeshi I., (2016). Proposal of appropriate compaction method using vibrator in different type of concrete, Proceedings of the Concrete Structure Scenarios, JSMS, Vol. 16.

Masayuki H., Isamu Y., Akinori H., and Yukihisa I. (2014). Evaluation of air bubbles distributed on concrete surface of side wall of tunnel living, Cement Science and Concrete Technology, Vol.67.

Japan Society of Civil Engineering (JSCE). (2008). Concrete engineering series 80. 